\title{
O FINANCEIRO E O IMOBILIÁRIO NA REESTRUTURAÇÃO DAS METRÓPOLES BRASILEIRAS
}

\author{
Daniel de Mello Sanfelici \\ Doutorando Geografia Humana - Universidade de São Paulo \\ danielsanfelici@gmail.com
}

Resumo

Esse trabalho visa interpretar as mudanças recentes nas regiões metropolitanas brasileiras acarretadas por megaprojetos de incorporação imobiliária e por uma reestruturação inédita do setor imobiliário no país. 0 trabalho argumenta que essas mudanças só podem ser compreendidas se pusermos em foco os novos nexos que vêm sendo estabelecidos entre o sistema financeiro e o mercado imobiliário. A primeira parte, discorre acerca das diferentes fases do processo de criação de um sistema de um crédito imobiliário no Brasil capaz de canalizar recursos excedentes para a produção do ambiente construído. $\mathrm{Na}$ segunda parte, discutimos como as grandes incorporadoras, tirando proveito da abundância de recursos para financiar a produção habitacional, têm causado mudanças ímpares na configuração espacial e, por extensão, na vida cotidiana das grandes cidades brasileiras.

Palavras-chave: Financiamento imobiliário; financeirização da habitação; valorização imobiliária; reestruturação socioespacial

\begin{abstract}
This paper aims to interpret the recent changes in metropolitan areas in Brazil caused by massive property development projects and by an unprecedented restructuring of the property sector in the country. The paper argues that these changes cannot be understood unless we pay attention to the new connections being established in Brazil between the financial sector and property development. The first part of the article, then, briefly describes the different phases of the creation of a mortgage system in Brazil capable of channeling surplus money-capital into the production of the built environment. In the second part, we have discussed how large developers, taking advantage of the abundance of capital for financing the production of the built environment have been causing fundamental changes in the spatial configuration and, therefore, in everyday life in Brazilian cities.
\end{abstract}

Key Words: Mortgage finance; financialization of housing; property development; socio-spatial restructuring.

\section{INTRODUÇÃO}

O propósito dessa contribuição consiste em oferecer um conjunto de reflexões teóricas acerca das metamorfoses socioespaciais que vêm redefinindo as metrópoles brasileiras nos anos recentes e engendrando profundas transformações na vida cotidiana. A magnitude dessas metamorfoses, bem como as direções para onde apontam, estariam sugerindo, segundo a concepção que embasa o presente trabalho, a necessidade de se repensar as metrópoles em sua relação com os negócios em torno da propriedade privada do solo e com os circuitos mais extensivos do capital financeiro globalizado. Essa reconsideração do papel dos negócios com a propriedade do solo é necessária uma vez que existem evidências suficientes para sugerir que a urbanização brasileira ingressou em uma fase substancialmente diferente nos últimos anos. Seria um contrassenso tentar condensar os traços dessa nova fase em poucos parágrafos, mas é forçoso frisar que novas relações vêm se esboçando entre o Estado e o urbano e entre os circuitos globalizados do capital e a produção do espaço urbano. Dificilmente houve, antes, liames tão estreitos vinculando as transformações mais locais (a "ordem próxima" dos bairros e comunidades) com negócios financeiros de extensão global. Acompanhando essas mudanças, delineiam-se transformações não menos significativas no esqueleto político e institucional que coordena e regulamenta os termos da produção do espaço urbano nas diferentes escalas. A urbanização e a produção do espaço adquiriram, como resultado, um caráter inegavelmente global, como já prenunciava Henri Lefebvre (2000; 2003). 
Esse trabalho pretende oferecer uma contribuição para desvendar as novas determinações do processo de urbanização em sua relação complexa com os negócios em torno da propriedade privada do solo urbano. Para tanto, esboçamos, na primeira parte, uma gênese histórica do aparato político-institucional que viabiliza a circulação do capital financeiro no ambiente construído urbano no Brasil. A necessidade desse percurso decorre de um entendimento de que as transformações recentes no sistema de crédito e, mais especificamente, no financiamento à produção do ambiente construído estabelecem um contexto socioeconômico imprescindível para que possamos compreender a explosão de negócios com a propriedade da terra urbana nos últimos anos.

Em seguida, no que constitui a parte central do artigo, procuramos examinar e interpretar os efeitos e desdobramentos desse quadro de mudanças sobre o processo de urbanização contemporâneo e sobre a tessitura espacial das metrópoles. O ponto de partida é o reconhecimento do surgimento de novos (e poderosos) agentes implicados na produção do espaço urbano, aptos a maximizar os ganhos provenientes da captura (privada) das riquezas produzidas socialmente pelo processo de urbanização. Examinar a atuação desses agentes constitui um passo inicial para que possamos compreender a rapidez com que as cidades brasileiras vêm se transformando nos anos recentes e em que sentido essas mudanças exercem seus efeitos sobre a vida cotidiana na metrópole. Como deverá ficar implícito ao longo da exposição, por trás da euforia dos mercados imobiliários em crescimento acelerado, é urgente ler os sinais que apontam para uma profunda crise da sociabilidade urbana e da reprodução social sob o capitalismo. Somente de tal forma se pode reconhecer o significado do urbano na atualidade.

\section{O PANORAMA ECONÔMICO-INSTITUCIONAL: aproximações preliminares acerca da criação de um sistema de crédito imobiliário no Brasil}

Uma miríade de condições sociais, econômicas, políticas e institucionais devem ser preenchidas para que ocorra a circulação do capital no ambiente construído - ou seja, para que o capital, cuja essência só pode se realizar com a expansão ininterrupta do seu valor, possa ser investido lucrativamente na construção das formas espaciais necessárias à reprodução global da sociedade. Uma vez que essas condições sejam, em maior ou menor grau, preenchidas, a circulação do capital no ambiente construído adquire relativa autonomia em relação aos circuitos de capitais envolvidos com a atividade produtiva e comercial, cristalizando-se em torno de um conjunto de instituições e regulamentações que viabilizam a transferência contínua dos capitais excedentes originados na produção industrial e no comércio para a formação de capital fixo de longo prazo (HARVEY, 1999).

Duas mudanças devem correr paralelas, portanto, para que se concretize essa transferência de capitais de maneira a propiciar o investimento em infraestruturas de circulação, produção e consumo - tais como rodovias, ferrovias, sistemas de esgoto, depósitos, portos, prédios comerciais e residenciais, fábricas, etc. Uma primeira mudança refere-se à necessidade de um vigoroso processo de acumulação de capital em atividades produtivas e comerciais. Essa acumulação deve ser capaz de gerar capitais excedentes que possam, por intermédio de um sistema de crédito, ser transferidos para financiar a formação de capital fixo de longo prazo. A segunda mudança envolve a elaboração de um arcabouço institucional que regule, fiscalize e coordene a formação e continuidade de um sistema de crédito sofisticado. Essa segunda mudança situa-se, evidentemente, na órbita das instituições do Estado moderno .

A história da formação de mercados imobiliários e de terras mais aprimorados é simultaneamente a longa história de um lento, mas inexorável entrelaçamento entre os interesses financeiros e os interesses 
relacionados com propriedade do solo. Marx já notava, em O Capital (MARX, 1990), a tendência secular à dissolução de interesses independentes girando em torno da propriedade da terra e a mudança de natureza desta última quando inserida nos circuitos da valorização do capital e na estrutura de classes da sociedade moderna. David Harvey (1999) assinala que, quando essa transformação se consubstancia, a propriedade do solo passa a ser equiparável a qualquer forma de capital fictício, tendo seu preço fixado pela capitalização da renda que esse ativo proporciona. Desse modo, a produção do ambiente construído ingressa, ainda que com relativa independência, no processo de circulação do capital, constituindo o que Harvey designou como circuito secundário, do qual participam diferentes agentes desempenhando diferentes papéis .

A formação de um mercado de terras e imobiliário mais sofisticado no Brasil passou por pelo menos três fases, a última das quais interessa mais porque configura o pano de fundo das rápidas transformações recentes das cidades brasileiras, problema que será abordado no item seguinte desse trabalho.

Até meados dos anos 1930, década considerada um divisor de águas na história da sociedade brasileira em virtude da aceleração do processo de industrialização, a integração entre os circuitos do capital financeiro e os mercados de terra e da construção era frágil. As razões para essa fragilidade são relativamente fáceis de discernir: em primeiro lugar, o mercado financeiro no Brasil era bastante limitado, seja em termos de volume de transações ou no que se refere à diversidade de instrumentos disponíveis; por outro lado, não havia um mercado de terras e da construção civil suficientemente vigoroso para estimular a integração com um sistema de crédito mais desenvolvido. Além das razões óbvias de que a acumulação de capital era francamente insuficiente para alimentar a formação de um mercado imobiliário mais robusto, a fragilidade desse mercado decorre, outrossim, da própria estrutura de provisão habitacional que prevaleceu antes de 1930.

A maior parte da população, nesse período, alugava a residência em que habitava. Isso criava obstáculos para as empresas de incorporação e construção, pois a demanda por novas construções refletia as oscilações no mercado de aluguéis - quando os aluguéis subiam, os investidores encomendavam novas construções; quando caíam, as encomendas rareavam. Em decorrência dessa instabilidade, as empresas de construção eram pequenas e, muitas vezes, tinham vida curta. Os ganhos mais vultosos eram auferidos, nesse período, com o parcelamento e revenda de glebas nas franjas das cidades em expansão. Em todas as grandes cidades brasileiras, o período da Primeira República foi de intensa especulação com terras urbanas. Laços pessoais e apadrinhamentos de todo gênero proporcionavam, para os grupos ou indivíduos loteadores, privilégios na extensão de serviços públicos (como linhas de bonde, rede de eletricidade, água encanada, etc), ao passo que inexistiam leis rigorosas normatizando o uso e a ocupação do solo urbano. Todas essas circunstâncias proporcionaram ganhos extraordinários aos proprietários das áreas loteadas - frequentemente chácaras nas adjacências do perímetro urbanizado .

Os anos 1930 marcam o início de uma tentativa, por parte do Estado, de regulamentar e coordenar os fluxos de capitais investidos no ambiente construído, assim como de subsidiar projetos de moradias populares, inaugurando uma nova fase na relação entre o financeiro e o imobiliário. Principalmente a partir dos anos 1940, o Estado brasileiro empenha-se em estimular o direcionamento dos recursos concentrados nas instituições de previdência para financiar a compra de moradias . É então que começa a se desenhar uma indústria imobiliária mais sofisticada, capaz de aplicar seus capitais em projetos de maior envergadura, como grandes edifícios comerciais e residenciais nos centros das principais metrópoles .

Em que pese esse incipiente esforço de canalizar recursos para financiar a construção e aquisição de moradia, até os anos 1960 não havia um sistema de financiamento habitacional propriamente dito, am- 
parado em uma relação sólida e estável entre o setor financeiro e a produção do ambiente construído. O investimento imobiliário era, apesar de tudo, limitado, se comparado ao período pós-64: por um lado, o mercado de aluguéis perdera boa parte da atratividade de que gozara até 1930-40 em decorrência de leis como a Lei do Inquilinato, de 1942, que congelou aluguéis com a intenção de desestimular a aplicação de recursos imprescindíveis à industrialização na especulação improdutiva com terrenos e moradias; por outro lado, o crédito para aquisição de moradias ainda atingia parcela reduzida da população.

A instalação do regime ditatorial militar em 1964 representou uma virada importante na política habitacional e na regulamentação dos elos entre o setor financeiro e a produção do ambiente construído. A aceleração da modernização do país, as medidas de regulamentação de um mercado de capitais e o advento de uma política habitacional centralizada sob a tutela do Banco Nacional da Habitação (BNH) viabilizaram uma canalização mais expressiva de recursos para a produção do ambiente construído urbano. Paralelamente, e em grande parte como resultado dessas transformações institucionais, ocorria uma abrangente reorganização do setor imobiliário e da construção civil, com a formação de empresas incorporadoras de maior porte especializadas na construção de moradias e prédios comerciais nas principais cidades do país, cujo crescimento populacional foi acelerado entre 1960 e 1980 .

Como um parêntense, vale frisar que, ainda que tenha sido amplamente utilizada como instrumento ideológico para conter as reivindicações populares crescentes da década de 1960, a política habitacional do período militar raramente contemplou as famílias mais necessitadas. A lógica que presidia a aplicação dos recursos acumulados provenientes das poupanças compulsória (o Fundo de Garantia por Tempo de Serviço - FGTS) e voluntária era a da remuneração plena do capital financeiro. Mesmo as cooperativas habitacionais (Cohabs) acabaram, em muitas ocasiões, por direcionar seus projetos para classes médias, dada sua maior capacidade de pagamento. (ARRETCHE, 1990; AZEVEDO e RIBEIRO, 1996; BOTELHO, 2007; ROYER, 2008).

Da perspectiva do volume de capitais excedentes transferidos para financiar a produção do ambiente construído, porém, esse esqueleto institucional funcionou relativamente bem até meados dos anos 1980 . Ano após ano, cresciam o número de contratos de financiamento e de unidades financiadas com recursos da poupança voluntária e compulsória. A década de 1980, que de modo geral sinalizou o esgotamento do modelo de crescimento econômico assentado no endividamento externo adotado pelos sucessivos governantes do período militar, explicitou as contradições contidas na política habitacional pós-1964. A dependência que o SFH possuía em relação aos recursos oriundos do FGTS e das cadernetas de poupança fez com que a crise de acumulação dos anos 1980 produzisse reflexos imediatos na capacidade de dar continuidade ao financiamento à habitação e à urbanização. Isso porque, à medida que a crise se agravava e que o desemprego aumentava, o Sistema Financeiro Habitacional era solapado nas duas pontas: de um lado, os recursos do FGTS e da poupança escasseavam; de outro, a inadimplência dos mutuários atingia níveis elevados, comprometendo a remuneração do capital financeiro. Em outras palavras, o que ocorreu foi que a instável compatibilidade entre os horizontes temporais de investimentos de curto e longo prazo entrou em colapso, o que culminou com a dissolução do BNH em 1986. (MELO, 1990; ARRETCHE, 1990; ROYER, 2008).

O período que compreende o colapso do BNH até meados da década de 1990 foi marcado por sucessivas experimentações de políticas habitacionais visando reativar o fluxo de capitais para o financiamento da moradia e da infraestrutura urbana. A maior inovação, porém, veio em 1997, com a aprovação de proposta de lei instituindo o Sistema de Financiamento Imobiliário (SFI). Dentre as mudanças mais relevantes introduzidas pelo SFI estão a figura da alienação fiduciária, que proporciona maior facilidade de retomada do imóvel pelos credores na eventualidade de inadimplência do mutuário, e as diversas 
formas de flexibilização das dívidas de hipoteca, abrindo caminho para a criação futura de um mercado secundário de títulos hipotecários semelhante ao existente em países como os EUA.

Não poderemos, aqui, examinar todos os desdobramentos produzidos pela instituição do SFI. Convém destacar, todavia, que as medidas criadas com o propósito de salvaguardar os credores do risco de inadimplência (em outros termos, do risco de desvalorização do capital fictício) criaram as condições para uma maciça canalização de recursos para a produção do espaço construído urbano. As razões para que essas tendências tenham se concretizado apenas parcialmente residem na insistência dos sucessivos governos pós-Plano Real em manter as taxas de juros em um patamar elevado, tornando, assim, sempre atrativa a aquisição de títulos da dívida pública, em detrimento do financiamento habitacional. Ainda assim, dados indicam um forte incremento no financiamento à moradia nos últimos anos, em particular com recursos da caderneta de poupança . Esses dados mostram, ademais, que um volume significativo do crédito imobiliário disponível tem sido direcionado para atender famílias de estratos de renda média e média-baixa (entre 3 e 10 salários mínimos).

Paralelamente a esse empenho recente em construir um aparato regulatório propício ao estreitamento dos elos entre o sistema de crédito e a produção do espaço, observam-se, nos últimos anos, rápidas transformações na tipologia das empresas líderes do setor imobiliário. Muito embora venha ocorrendo desde os anos 1970 uma tendência à centralização do capital no setor construtivo e incorporador, nos últimos dez anos essa tendência se acelerou de maneira inaudita, e seus efeitos estão mais visíveis nas principais metrópoles brasileiras. As grandes incorporadoras imobiliárias são, hoje, empresas nacionais ou internacionais de capital aberto, dispõem de estoques de terrenos (land banks) cuja soma de preços alcança patamares estratosféricos, estão preferencialmente sediadas em São Paulo e investem em projetos cada vez mais ambiciosos.

A convergência dessas mudanças de natureza institucional, política e econômica vem favorecendo, de inúmeras maneiras, a circulação do capital no ambiente construído urbano e a captura de rendas do solo urbano por parte do capital financeiro globalizado. À medida que os nexos entre a produção do ambiente construído e a circulação do capital a juros são fortalecidos, o espaço social vai sendo com maior vigor arrastado para o interior das contradições explosivas do capitalismo global. A volatilidade e a instabilidade características da atual fase do capitalismo ganham expressão espacial na rapidez (e robustez) com que o tecido urbano é reestruturado sob o efeito do revigoramento dos negócios com a propriedade do solo. É para essas reestruturações que agora nos voltamos.

\section{AS NOVAS DETERMINAÇÕES DO PROCESSO DE URBANIZAÇÃO: valorização acelerada do solo urbano e reestruturação socioespacial}

Esse panorama delineado nos parágrafos anteriores permite contextualizar a miríade de transformações que vem afetando o processo de urbanização no Brasil. No que segue, pretendemos registrar algumas dessas mudanças com o fito de contribuir para desvendar os novos determinantes da urbanização brasileira e seus desdobramentos na vida cotidiana das metrópoles. Em que pese teor mais conceitual, a discussão que segue deve tributo, em larga medida, a resultados parciais obtidos em pesquisa em andamento, bem como a resultados de pesquisa anterior, em ambos os casos lidando com a reestruturação socioespacial da metrópole de Porto Alegre .

Talvez seja pertinente iniciar observando com mais atenção a já mencionada reestruturação administrativa e empresarial em curso no setor imobiliário brasileiro. É essa reestruturação que tem sido responsável por modificar os modos pelos quais vêm se efetivando os ganhos com o giro da propriedade do solo.

Revista da ANPEGE. v. 6, 2010 (jan./dez.) 
Desde os anos 1990, vem ocorrendo um processo de centralização do capital e dispersão do alcance geográfico das empresas no setor de construção e incorporação imobiliária. Esse processo consolida tendências que já podiam ser vislumbradas na década de 1970, período em que começa a se fortalecer um setor imobiliário moderno nas principais cidades do país. As principais diferenças, em relação à década de 1970, residem na capacidade que as empresas têm de levantar recursos e de atuar simultaneamente em diferentes mercados. O surgimento de novas formas de capitalização, como a abertura de capital na Bolsa de Valores, viabilizou, para as grandes incorporadoras, a aquisição de empresas regionais e locais e expansão do estoque de terrenos. Tomando como exemplo o caso de Porto Alegre, abaixo encontram-se listadas as empresas de fora da capital gaúcha que vêm investindo nesse mercado.

Essa tabela é representativa do que vem ocorrendo na maior parte das regiões metropolitanas brasileiras. As firmas tradicionais, de atuação local e frequentemente com estrutura administrativa e organizacional familiar, vêm perdendo espaço para empresas de maior porte, de capital aberto e apresentando crescente separação de gestão e propriedade, uma mudança registrada por Ball (1983) no caso da Inglaterra. As maneiras em que isso ocorre são variadas, e estão representadas na amostra selecionada para a tabela. Algumas empresas ingressam nos mercados locais estabelecendo escritórios regionais e atuando independentemente. Esse é o caso, por exemplo, da Rossi Residencial, que vem rapidamente se firmando, nas grandes cidades brasileiras, na fatia de mercado especializada em residências para famílias de classe média baixa (embora a empresa também invista em outros segmentos). A Cyrela pratica um misto de aquisições de empresas locais, atuação independente e parcerias. Com a Goldsztein, a Cyrela esteve envolvida em duas dessas formas de intervenção. Primeiramente, em 2005, a empresa estabeleceu uma parceria (joint venture) com a Goldsztein para operar no mercado econômico. Poucos anos depois, em 2009, a empresa adquiriu a outra metade da Goldsztein . Outras empresas, como a Rodobens, a Gafisa e a Even vêm operando através de parcerias com empresas locais.

Todas elas, porém, compartilham um conjunto de características. São empresas de capitais volumosos e que produzem um número elevado de unidades residenciais por ano. Ademais, sua presença se faz sentir em um número elevado de estados. Por fim, todas declararam lucros volumosos para o ano de 2009, em que pese a cautela financeira que predominou nesse ano em virtude da recessão econômica global.

Não é nosso propósito examinar com maior rigor o desempenho financeiro e administrativo das incorporadoras. O que importa, aqui, é entender de que modo essas mudanças se relacionam com a maneira como a valorização imobiliária vem redefinindo o tecido socioespacial das metrópoles. Isso porque, como resultado da reestruturação do setor imobiliário e do volume crescente de recursos para financiar a habitação, mudou a maneira e a rapidez com que ocorre a valorização imobiliária de segmentos do espaço metropolitano.

No âmbito dessa discussão, cumpre notar, em primeiro lugar, o papel singular desempenhado pelos megaprojetos imobiliários em estabelecer as linhas de frente da valorização acelerada do espaço urbano. São projetos que, em virtude de sua envergadura e do dispêndio elevado em publicidade que os acompanha, abrem as portas para novos investimentos em suas adjacências que podem, em poucos anos, converter uma área pouco valorizada em um novo eldorado do mercado imobiliário. Suas feições podem variar: grandes shopping centers combinados com torres de escritórios; "bairros planejados" com áreas verdes, edifícios residenciais e de escritórios; condomínios horizontais e verticais de grande porte com atrativos diferenciados; loteamentos cercados equipados com áreas de lazer e entretenimento, etc. Em todos os casos, tem havido uma nítida tendência à combinação de funções (residencial, comercial e de escritórios) no interior de um mesmo empreendimento ou em áreas circundantes. 


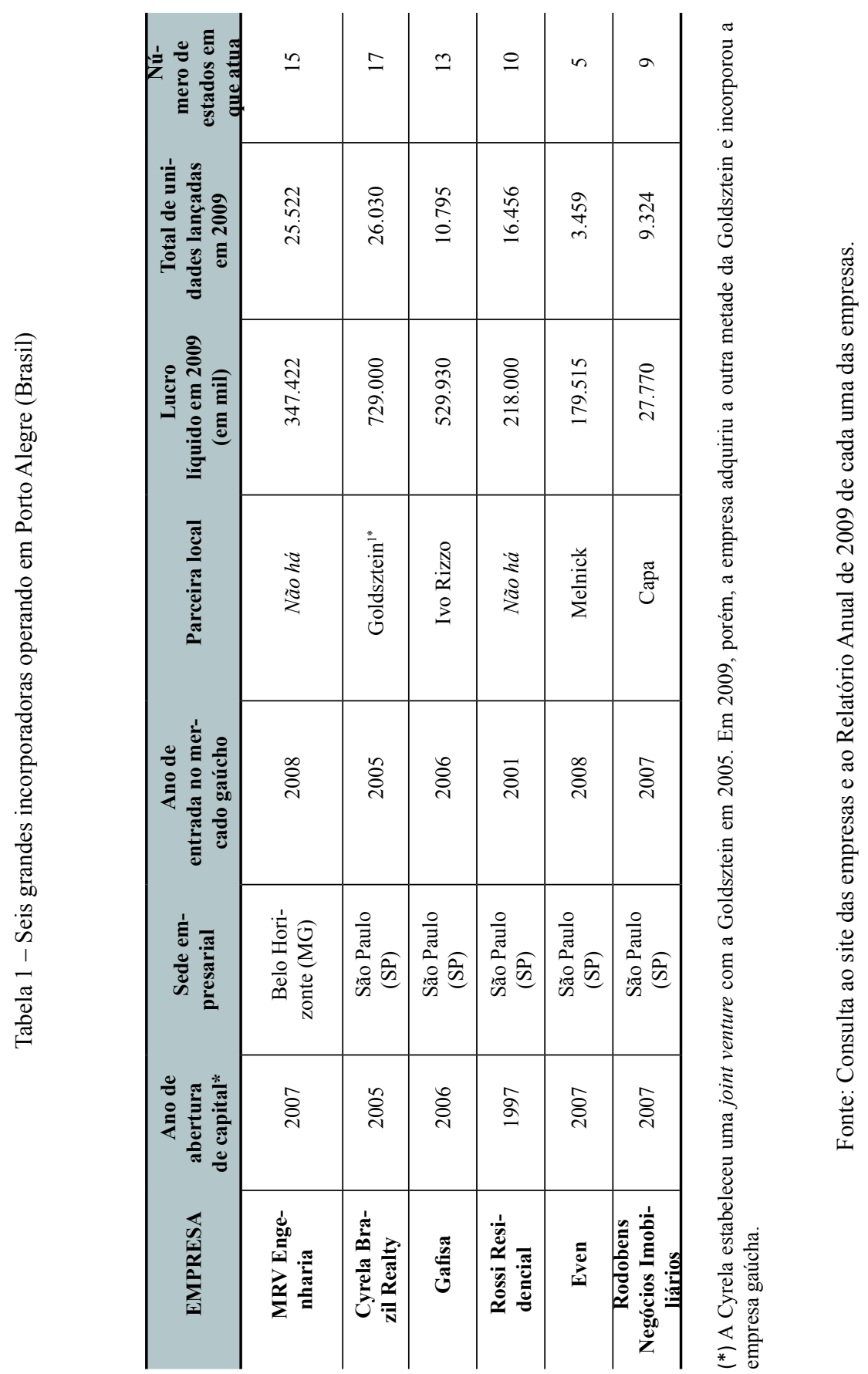

Revista da ANPEGE. v. 6, 2010 (jan./dez.) 
O interessante aqui, além disso, é notar a capacidade redobrada que as grandes empresas possuem de transformar áreas pouco valorizadas em novas fronteiras urbanas e o papel que essas fronteiras urbanas cumprem do ponto de vista das estratégias de rentabilidade de longo prazo das incorporadoras . O elevado volume de recursos direcionados para esquemas publicitários permite conferir uma aura de prestígio a áreas antes pouco interessantes do ponto de vista do investimento imobiliário. Isso rapidamente eleva a renda da terra potencial disponível em uma determinada área, gerando ganhos extraordinários para as incorporadoras como resultado da captura do diferencial de renda (o que Neil Smith (1996) denominou rent gap). É assim que, ao serem produtoras de novas centralidades, as grandes incorporadoras conseguem se emancipar, ao menos em parte, da necessidade de ofertar empreendimentos de alto padrão exclusivamente em áreas de valorização já consolidadas da metrópole. Em outras palavras, as novas fronteiras urbanas estão mais dispersas, refletindo o poder econômico concentrado desses agentes produtores do espaço. Ao caracterizar o que designaram por "terceira fase" da gentrification, Jason Hackworth e Neil Smith observam que

[...] a valorização [gentrification] está avançando tanto nos bairros mais próximos à área central, que haviam sido afetados nas duas primeiras fases, quanto em bairros mais remotos para além desse núcleo central. [...] [A] restruturação e a mundialização do indústria imobiliária estabeleceram o contexto para que as grandes incorporadoras se envolvessem nos bairros em processo de enobrecimento [gentrification]. Se antes essas grandes incorporadoras costumavam ingressar no processo somente depois que o bairro em questão tivesse sido "domesticado", agora elas são crescentemente as primeiras a orquestrar a revalorização (HACKWORTH \& SMITH, 2001, p. 468) .

A esse tipo de investimento de alto padrão em áreas mais distanciadas dos bairros tradicionalmente valorizados combina-se a recente atratividade, viabilizada pela ampliação da oferta de crédito imobiliário, dos negócios imobiliários destinados a famílias de renda média-baixa. Também nesse segmento o apelo aos megaprojetos é grande: proliferam grandes condomínios verticais, compostos de várias torres, com extensas áreas de lazer, localizados nas franjas do tecido metropolitano, onde o preço dos terrenos para incorporação é mais baixo. Para atender essa classe média, grandes estruturas comerciais, como hipermercados e shopping centers, multiplicam-se em áreas distantes, estimulando o uso do automóvel como meio de transporte preferencial.

É preciso, ainda, enfocar os nexos estatistas que atualizam e potencializam a rentabilidade dos negócios com a propriedade do solo urbano. O Estado vem atuando em frentes diferentes. Ora ele concorre para flexibilizar a realização da propriedade do solo através da venda de potenciais construtivos (é o caso dos CEPACs - Certificados de Potencial Adicional de Construção, em São Paulo, que podem ser infinitamente renegociados); ora o Estado intervém como agente direto da valorização imobiliária, seja através de instrumentos como as operações urbanas, que canalizam vultosos recursos para os fragmentos gerenciais das metrópoles, seja através das inúmeras formas de parceria público-privada para intervenção maciça no espaço urbano .

A ponta de lança desse gênero de intervenção facilitadora de grandes negócios deverá se descortinar nos próximos anos no Brasil, com efeitos semelhantes aos já verificados em outros países. Referimonos às colossais intervenções que serão necessárias para abrigar megaeventos esportivos como a Copa do Mundo de 2014 (com 12 cidades-sede) e os Jogos Olímpicos de 2016 (este no Rio de Janeiro). São megaprojetos cujos riscos tendem a ser assumidos pelo Estado, mas dos quais a iniciativa privada poderá extrair volumosos ganhos. Ainda convém frisar que aqueles negócios que, à primeira vista, podem parecer pontuais - a reforma ou construção de um estádio, por exemplo - deverão ter reverberações sobre todo 
o tecido metropolitano, redefinindo centralidades e deslanchando ondas especulativas cujos perímetros não se limitam à área onde a intervenção é realizada.

Todas essas mudanças vêm tornando mais complexos os sentidos que devem ser atribuídos ao conceito de fragmentação socioespacial. Novas linhas de fraturas socioespaciais atravessam o espaço metropolitano em toda sua extensão, incluindo as extensas periferias que agora recebem suas próprias versões de enclaves fortificados para a classe média baixa. As práticas cotidianas, por sua vez, espelham esse recrudescimento da fragmentação do espaço urbano. As classes médias e altas vêem seus percursos cotidianos tanto mais reduzidos quanto mais se multiplicam os projetos de urbanização multifuncional, em que áreas residenciais combinam-se com edifícios de escritório, hipermercados e shopping centers em fragmentos restritos do tecido metropolitano. A nova onda de "bairros planejados" e condomínios fechados de alto padrão aparta essas classes do contato com outros espaços que não os espaços modernizados e mediados pelos signos onipresentes e ordenantes do consumo e pela ideologia da segurança na e pela reclusão. A parcela da classe média com rendimentos mais baixos, por sua vez, mimetiza precariamente esse estilo de vida em condomínios fechados nas bordas menos valorizadas da metrópole, consumindo horas do seu dia em longos trajetos de automóvel para o local de emprego e utilizando grandes equipamentos de consumo como hipermercados em suas compras diárias. Há aqui um incontestável empobrecimento daquilo que se possa entender por experiência urbana na atualidade.

É na espessa base da pirâmide social, contudo, que os moradores suportam o fardo da crise reprodutiva da sociedade mercantil-capitalista. Nas suas práticas e identidades cotidianas estampa-se a desintegração social que coloca o Brasil na "vanguarda" do colapso e da flexibilização das relações sociais, como ironicamente sugeriu Paulo Arantes (2004). A desintegração atinge, aí, todos os momentos da vida urbana e atualiza e ressignifica, potencialmente, a noção de proletarização, nos termos que Damiani $(2008 ; 2009)$ vem explorando. Muitas vezes a família ou a vizinhança (ou os restos de ambas) aparece como último refúgio diante das incertezas e inseguranças da vida cotidiana na periferia. Kowarick, discorrendo acerca da "condição periférica" nas grandes metrópoles, assinala que

[...] em face da estreiteza dos canais institucionais para manutenção e conquista dos direitos sociais, em face da inexistência de proteção quanto aos direitos civis mais elementares e em consequência da incivilidade que marca as relações sociais nos espaços públicos, onde prevalece arrogância e privilégio, muitos se refugiam na sociabilidade primária da família, amigos, parentes ou conterrâneos: estruturada em torno da casa e da vizinhança, desses pedaços reconhecidos como solidários, de proteção e ajuda mútua, muitos organizam formas defensivas para enfrentar as múltiplas violências que marcam o dia a dia na metrópole [...] (KOWARICK, 2000, p. 115)

De tal maneira, as metrópoles vão sendo, de todos os lados, reconfiguradas em uma "explosão" de fragmentos desconexos, costurados primordialmente pela ação totalizante do Estado e pelas ideologias que obscurecem a crise mesmo quando ela já permeia todas as dimensões da vida urbana. O desafio teórico-metodológico reside em desvendar o sentido e o papel dos negócios com a propriedade do solo em injetar ânimo à acumulação de capital e, ao fazê-lo, reproduzir as metrópoles como lugar do possível negado, da precariedade e da insegurança como condição de existência de milhões de indivíduos.

\section{CONSIDERAÇÕES FINAIS}

À guisa de considerações finais, valeria a pena retomar o fio condutor das problematizações e questões levantadas nos parágrafos anteriores, para reiterar a trajetória percorrida.

Revista da ANPEGE. v. 6, 2010 (jan./dez.) 
Nos últimos vinte anos vem ocorrendo uma transformação qualitativa importante nas conexões existentes entre o mercado financeiro e a produção do ambiente construído urbano no Brasil. Essa transformação aponta para uma redefinição do sentido da propriedade privada do solo urbano ao amarrá-la a circuitos intricados de remuneração financeira cujas conexões ultrapassam as fronteiras nacionais. $\mathrm{O}$ imobiliário vai, de tal maneira, despindo-se paulatinamente de sua tradicional rigidez para acertar o passo com os investimentos próprios dos mercados financeiros, numa onda de "flexibilizações" que só pode ser explicada por uma escassez (possivelmente global) de oportunidades lucrativas de investimento, ver nesse contexto as reflexões de Brenner (1998; 2003), Harvey (2003; 2005) e Chesnais (2007). É provável que essas transformações estejam conferindo um novo sentido ao processo de urbanização, o que reforça a necessidade de se pensar globalmente a produção do espaço e suas contradições. Esse foi o sentido dos problemas abordados na primeira parte do presente artigo.

Esse novo cenário econômico e institucional, por sua vez, encontra-se intimamente atrelado à emergência de novos agentes na produção do espaço: as grandes incorporadoras, altamente capitalizadas e capazes de investir simultaneamente em diferentes (e distantes) lugares. Sua atuação vem exigindo que repensemos a lógica do uso do solo urbano nas cidades brasileiras e as direções tomadas pelo processo de reestruturação socioespacial urbana. São novas estratégias que se desenham com o propósito de repor os patamares de rentabilidade possíveis com os negócios em torno da propriedade privada e da urbanização.

Os efeitos da valorização imobiliária desenfreada sobre o espaço urbano e sobre o cotidiano dos moradores é muitas vezes devastador. Comunidades inteiras são frequentemente varridas para dar lugar ao avanço das novas "fronteiras urbanas", provocando formas renovadas de espoliação. Mesmo áreas tradicionalmente de classe média vêm sendo radicalmente transformadas sob o ímpeto econômico dos megaprojetos de incorporação imobiliária. Ilustrativo a esse respeito é o caso do bairro Vila Olímpia, em São Paulo, estudado por Carlos (2001). Esse bairro foi, em questão de poucos anos, convertido de um bairro de classe média horizontalizado para um bairro de elevado valor do solo repleto de condomínios verticais e de torres de escritórios, como resultado da Operação Urbana Faria Lima.

No contexto dessas reflexões, seria importante perscrutar as novas conexões que se colocam entre a urbanização e a acumulação de capital. Não parece despropositado sugerir que esse "boom" imobiliário que, em uma espécie de efeito-dominó, vem atingindo uma série de países do mundo, tenha relações estreitas (e inegavelmente intricadas) com a escassez de escoadouros suficientes para absorver uma massa de capitais ociosos (sobreacumulados) em busca de investimentos rentáveis (onde quer que estejam). Se assim for, a valorização acelerada do espaço guardaria relação estreita com a profusão de rentismos que tem caracterizado esta etapa financeirizada do desenvolvimento capitalista . Essa é, em alguma medida, a tese que vem sendo propugnada por David Harvey (2008), ao sugerir que a urbanização e os vastos investimentos no ambiente construído na China e em outros lugares têm absorvido quantias imensas de capitais de toda parte do mundo. Que esse boom possa estar, assim como a valorização fictícia de ativos financeiros, assentado sobre terreno instável pouco tem-se explorado, em que pese o risco crescente associado ao ritmo acelerado de endividamento de parcelas significativas da população. De todo modo, a experiência recente dos Estados Unidos com o mercado secundário de hipotecas prenuncia em grande medida o que pode ocorrer em outros lugares caso a expansão da securitização de hipotecas avance para além de um certo patamar.

\section{REFERÊNCIAS BIBLIOGRÁFICAS}

ARANTES, Paulo. Zero à esquerda. São Paulo: Conrad, 2004.

ARRETCHE, Marta. Intervenção do Estado e setor privado: o modelo brasileiro de política habitacional. Espaço 
e debates, n. 31, 1990

AZEVEDO, Sérgio de; RIBEIRO, Luiz Cezar de Queiroz. A produção de moradia nas grandes cidades: dinâmica e impasses. In: AZEVEDO, Sérgio de \& RIBEIRO, Luiz Cezar de Queiroz (org.). A crise da moradia nas grandes cidades: da questão da habitação à reforma urbana. Rio de Janeiro: Editora UFRJ, 1996.

BALL, Michael. Housing policy and economic power: the political economy of owner occupation. London: Methuen, 1983.

BOTELHO, Adriano. O urbano em fragmentos. São Paulo: Annablume/FAPESP, 2007.

BRENNER, Robert. O boom e a bolha: os Estados Unidos na economia mundial. Rio de Janeiro: Record, 2003.

CARLOS, Ana Fani Alessandro. Espaço-tempo na metrópole. São Paulo: Contexto, 2001.

CHESNAIS, François. O capital portador de juros: acumulação, internacionalização, efeitos econômicos e políticos. In: CHESNAIS, François (org.). A finança mundializada. São Paulo: Boitempo, 2007.

DAMIANI, Amélia Luisa. A metrópole na dialética entre o território da ação estatista e o espaço de projeto político. In: CAMPOS, Andrelino; SILVA, Catia Antonia da (org.). Metrópoles em mutação: dinâmicas territoriais, relações de poder e vida coletiva. Rio de Janeiro: Revan/FAPERJ, 2008.

DAMIANI, Amélia Luisa. Urbanização crítica e produção do espaço. Cidades. Presidente Prudente: Grupo de Estudos Urbanos, v. 6, n. 10, 2009.

GOTHAM, Kevin Fox. The secondary circuit of capital reconsidered: globalization and the U.S. real estate sector. American Journal of Sociology. Volume 112, N. 1, July 2006.

GOTHAM, Kevin Fox. Creating liquidity out of spatial fixity: the secondary circuit of capital and the subprime mortgage crisis. International Journal of Urban and Regional Research. Vol. 33.2, June 2009, p. 355-76.

HACKWORTH, Jason; SMITH, Neil. The changing state of gentrification. Tijdschrift voor Economische en Sociale Geografie. 92 (4): 464-477, 2001.

HARVEY, David. The limits to capital. New York: Verso, 1999.

HARVEY, David. The new imperialism. Oxford: Oxford University Press, 2003.

HARVEY, David. A brief history of neoliberalism. Oxford: Oxford University Press, 2005.

HARVEY, David. The right to the city. New Left Review, 53, pp. 23-40, Sep/Oct 2008.

KOWARICK, Lúcio. Escritos urbanos. São Paulo: Editora 34, 2000.

LEFEBVRE, Henri. La production de l'espace. Paris: Anthropos, 2000.

LEFEBVRE, Henri. The urban revolution. Minneapolis: University of Minnesota Press, 2003.

MARX, Karl. Capital: a critique of political economy. New York: Penguin, 1990, 3 vol.

MELO, Marcus André B. C. de. Regimes de acumulação, Estado e articulação de interesses na produção do espaço construído (Brasil, 1940-1988). In: VALLADARES, Licia; PRETECEILLE, Edmond (orgs.). Reestruturação urbana: tendências e desafios. Rio de Janeiro: Nobel/IUPERJ, 1990.

RIBEIRO, Luiz César de Queiroz. Dos cortiços aos condomínios fechados: as formas de produção da moradia na cidade do Rio de Janeiro. Rio de Janeiro: Civilização Brasileira, 1997.

SANFELICI, Daniel de Mello. A produção do espaço como mercadoria: novos eixos de valorização imobiliária em Porto Alegre/RS. São Paulo: FFLCH/USP, 2009. Dissertação de Mestrado.

Revista da ANPEGE. v. 6, 2010 (jan./dez.) 
SASSEN, Saskia. Mortgage capital and its peculiarities. Journal of International Affairs. Fall/Winter 2008, Vol. 62, N. 1.

SASSEN, Saskia. When local housing becomes an electronic instrument. International Journal of Urban and Regional Research. Vol. 33.2, June 2009, p. 411-26.

SEABRA, Odette Carvalho de Lima. Metropolização: a reprodução do urbano na crise do sociedade do trabalho. Cidades. Presidente Prudente: Grupo de Estudos Urbanos, v. 6, n. 10, 2009.

SINDUSCON-RS. Censo do Mercado Imobiliário de Porto Alegre (2009). Porto Alegre, 2009.

SMITH, Neil. The new urban frontier. New York: Routledge, 1996.

STROHAECKER, Tania. Atuação do público e do privado na estruturação do mercado de terras de Porto Alegre (1890-1950). Scripta Nova: Revista electrónica de geografia y ciencias sociales. Barcelona: Universidad de Barcelona, 2005, vol. IX, num. 194.

WEBER, Rachel. Extracting value from the city: neoliberalism and urban redevelopment. Antipode: a Radical Journal of Geography, 34,3 (2002): 519-540.

Recebido em outubro de 2009

Aceito em dezembro de 2009 